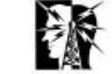

education \& training
DEPARTMENT OF HEALTH (2002)

Unfinished Business: Proposals for Reform of the Senior House Officer Grade. Department of Health.

DEPARTMENT OF HEALTH (2003)

Department of Health Vacancies

Surveys, March 2003. http://

www.dh.gov.uk/assetRoot/64/07/

93/75/04079375.pdf

EAGLES, J. M. (2004) Modernising

medical careers. Psychiatric Bulletin, 28, 425.

ERON, L. D. (1955) Effect of medical education on medical students

attitudes. Journal of Medical Education, 30, 559-566

GALEAZZI, G. M., SECCHI, C. \& CURCI, P. (2003) Current factors affecting the choice of psychiatry as a career: an Italian study. Academic Psychiatry, 27, $74-81$.

GOLDACRE, J. M., DAVIDSON J. M. \& LAMBERT,T.W. (2004) Country of training and ethnic origin of UK doctors: database and survey studies. BMJ, 329 597.

HALFORD, J. (2003) Invited commentary on: recruiting and retaining psychiatrists. Advances in Psychiatric Treatment, 9, 411-413.

HELD, M. L. \& ZIMET, C. N. (1975)A retrospective view of medical speciality choice. Journal of Medical Education 50, 2044-2051.

MCPARLAND, M., NOBLE, L. M., LIVINGSTON, G., et al (2003) The effect of a psychiatric attachment on students' attitude to and intention to pursue psychiatry as a career. Medical Education, 37, 447.

MAIDMENT, R., LIVINGSTON, G. KATONA, M., et al (2003) Carry on shrinking: career intentions and attitudes to psychiatry of prospective medical students. Psychiatric Bulletin 27, 30-32.

MAIDMENT, R., LIVINGSTON, G. KATONA, M., et al (2004) Changes in attitudes to psychiatry and intention to pursue psychiatry as a career in newly qualified doctors: a follow-up of two cohorts of medical students. Medical Teacher, 26, 565-569.

PRINS, H. (1998) Characteristics of consultant forensic psychiatrists (a modest survey). Journal of Forensic Psychiatry, 9, 139-149.
RAJAGOPAL, S., REHILL, K. S. \& GODFREY E. (2004) Psychiatry as a career choice compared with othe specialties: a survey of medical students. Psychiatric Bulletin, 28,444446.

SCHUMACHER, C. F. (1964) Personal characteristics of students choosing different types of medical careers. Journal of Medical Education, 39, 278 288.

SIERLES, F. S. \& TAYLOR, M. A. (1995) Decline of US medical student career choice of psychiatry and what to do about it. American Journal of Psychiatry, 152, 1416-1426.

SIVAKUMAR, K., WILKINSON, G. TOONE, B. K., et al (1986) Attitudes to psychiatry in doctors at the end of their post-graduate year: two-year followup of a cohort of medical students.

Psychological Medicine, 16, 457-460.

*Kalpana Dein Specialist Registrar in Forensic Psychiatry, North London Forensic Services, Chase Farm Hospital, The Ridgeway, Enfield EN2 8JL, email: kalthomas@yahoo.co.uk, Gill Livingston Professor of Psychiatry of Older People, Department of Mental Health Sciences, University College London, Christopher Bench Consultant Psychiatrist, West London Mental Health NHS Trust, The Claybrook Centre, LondonW6 8LN
THOMPSON, D. J. \& SIMS, A. C. P. (1999) Malaise in psychiatric recruitment and its remedy. Psychiatric Bulletin, 23, $227-229$

TUCKER, G.J. \& REINHARDT R. F (1968) Psychiatric attitudes of young physicians: implications for teaching. American Journal of Psychiatry, 124, 986-991.

WILKINSON, D. G., TOONE, B. K. \& GREER, S. (1983) Medical students' attitudes to psychiatry at the end of the clinical curriculum. Psychological

YAKELEY, J., SHOENBERG, P. \& HEADY, A. (2004) Who wants to do psychiatry? The influence of a student psychotherapy scheme - a 10 -year retrospective study. Psychiatric Bulletin, $28,208-212$. Medicine, 13, 655-658.

\title{
First experience of recruiting to the new specialist training programme
}

In 2002 Unfinished Business, a report and consultation paper by Sir Liam Donaldson, Chief Medical Officer for England, put forward proposals for the reform of the senior house officer (SHO) grade, including the formation of the new early years foundation posts (Donaldson, 2002). In 2004 Modernising Medical Careers - The Next Steps (Department of Health, 2004) outlined specialty and general practitioner (GP) training programmes building on the foundation programme. As a result all medical training will be changing to a competency-based model from August 2007. This will encompass runthrough training from specialist training years 1 (ST1) to 6 (ST6). Some regions and specialties have been chosen as pilot sites for specialist training year 1 commencing August 2006.

\section{Mersey Deanery pilot}

The Mersey Deanery has embraced the changes with enthusiasm and was a pilot site for foundation year 2 (F2) trainees in 2004, which included psychiatric placements. Psychiatry is one of the specialties that has agreed to take part in the ST1 pilot.

The Merseyside regional rotational training scheme has 93 trainees at SHO level spread over a large geographical area. Organisation of the scheme is carried out by three scheme coordinators, one from each of the largest local trusts, with input from local college tutors and specialties via the Basic Specialist Training and Education Committee (STEC). They are supported administratively by the medical staffing department of the single employing trust. Until now the scheme has been run much along the lines of most training schemes, with competitive interview, contracts being renewed on satisfactory progress and an expectation that trainees will progress quickly through years 1 to 3 and obtain their Membership of the Royal College of Psychiatrists before taking up higher postgraduate training.

For the new specialist training scheme it was considered that a more robust form of selection would be required if the right individuals were to be found for the 6 -year specialist training now proposed. A new recruitment and selection process was set up by the scheme organisers with help and advice from Mersey Deanery. It consisted of an application process, a shortlisting procedure and a competitive interview.

\section{Application process}

Advertisements appeared on the Mersey Deanery website (http://www.merseydeanery.nhs.uk) along with 
a person specification and in the BMJ. Applicants were required to download the application form and send in four paper copies. Human resources staff initially screened the applications for valid General Medical Council (GMC) registration.

The application form was in 11 sections:

- personal details

- GMC registration

- professional qualifications and experience, including prizes

- present employment

- previous appointments

- clinical care - knowledge and skills including evidence of $F 2$ training

- audit - a description of an audit project carried out by the candidate

- evidence-based medicine/research/presentations and publications - intended to demonstrate the candidate's understanding of these

- interpersonal skills and team work

- personal skills/personal statement/other interests

- referees

\section{Shortlisting}

Nominations were invited from local trusts for current educational supervisors to sit on the shortlisting and interview panels. Representation was sought from the academic department and specialties, and from carers' and users' groups. General adult psychiatry, old age psychiatry, psychotherapy, learning disabilities, child and adolescent mental health services, the local academic unit, and carers and users were all represented.

Fifteen panel members were identified and met on 2 days to shortlist from 186 eligible applications. The group split into 3 smaller groups of 5, each group reviewing 62 applications. The 3 scheme coordinators had devised, with wider consultation, a scoring sheet for evaluating the applications, allowing for a score out of 50 to be awarded. The scheme coordinators moved among groups in order to try to maintain some consistency in scoring. Each candidate was awarded a score by the group and this was entered on a spreadsheet by one of the administration staff.

\section{Interview schedule}

Although having a psychiatric bias, the interviews should not have been beyond the capabilities of any doctor who had undertaken house officer or foundation year training. It consisted of three parts, a traditional interview, a presentation and a practical skills assessment. Prior to the interview candidates' documents were checked by staff from medical staffing.

\section{Traditional interview}

The interview section of the assessment involved four interviewers, including a patient representative, and lasted for $20 \mathrm{~min}$. The interview was structured with four questions, the final question being subdivided into three parts. The questions were based on the F2 curriculum. All candidates were asked the same set of questions in the same order. They included questions about the applicants' reasons for choosing psychiatry as a career, their understanding of the process and purpose of audit, the role of alcohol in psychiatric and psychological morbidity and a clinical vignette to promote a discussion about mental capacity.

\section{Presentation}

Candidates were given the topic on arrival and allowed 30 min for preparation. No presentation aids (e.g. overhead projector or power point) were provided, however, candidates were advised they could make notes for use during the presentation, which was to be of no more than 5 min. The topic for the presentation was 'Discuss the reasons why some people develop mental disorders and others do not'.

The idea behind this station was to test not only the candidate's knowledge but also their ability to think on their feet and test their performance under pressure.

\section{Practical skills}

This took the form of an objective structured clinical examination (OSCE), lasting up to $10 \mathrm{~min}$, where actor patients were employed. The case scenario was that of a potentially suicidal patient and the task was to assess the current risk of suicide.

\section{Scoring system}

For each of the stations a comprehensive scoring sheet had been prepared. This was broken down into component parts for each station. The interview attracted a maximum score of 30 points, the presentation could score up to 20 points and the practical skills scenario also had a maximum score of 20 points. Each interviewer scored their station separately and was asked to make notes for subsequent analysis and to aid feedback (sample score sheets are available from the authors on request).

\section{Selection process}

The selection procedure took place over 2 days. Each candidate followed the same pattern of presentation, interview and practical skills for which $40 \mathrm{~min}$ had been allocated. There were two interview stations and one each of the other stations; starting times were staggered. The timetable was devised by medical staffing personnel who also acted as invigilators and timekeepers. The 15 individuals who had been involved in the shortlisting process were split among the four stations. In order to try to maintain consistency, the same interviewers were based on the same stations on both days and the content of the interviews remained the same. 
.

education \& training

\section{Results}

From 186 eligible applications, 64 candidates were shortlisted and 51 of these attended for interview. Shortlisting scores ranged from 1 to 40 , and those with a score of $\geqslant 22$ were shortlisted. The mean score for those shortlisted was 28.9, and for those who were not the mean score was 13.6.

Scores during the selection procedure ranged from 21.5 to 56.5 out of 70 . The 24 successful candidates scored 42 and over. There were seven reserve candidates scoring between 39 and 41.5. The mean score of successful candidates was 46.7 and that for unsuccessful candidates was 33.8

\section{Discussion}

Disadvantages of this type of selection process are that it is time-consuming and costly in terms of manpower; 12 consultant psychiatrists and three service users/carers were involved over 4 days. There were also 4 half-days of actor/patient time. The organisation and administration of the procedure took up many hours of human resources staff time.

In spite of the apparent drawbacks, the positive features were the cooperation between the scheme coordinators, other interviewers and human resources staff, which led to the interviews running smoothly and with no timing problems. Feedback from the users'/ carers' group about the process has generally been positive. The venue, an empty ward in a district general hospital, worked particularly well as it was possible to make use of bays as interview stations and side-rooms as a waiting area, documents checking station and presentation preparation areas.

Each candidate was asked the same questions in the same order at interview and carried out identical tasks in the presentation and practical skills station. It was hoped that this format would ensure consistency and reduce interviewer bias. However, we acknowledge limitations in the selection process, particularly as a single OSCE is not considered to be a reliable measure of clinical skills. This was our first experience of deviating from a traditional interview procedure and the format had to be devised within a limited timescale. Consideration will be given to a different procedure in future.

All scoring sheets were retained and unsuccessful candidates were invited to request feedback; six individuals took up the offer. The use of a comprehensive scoring system made this easier and more meaningful.

Next year all recruits to psychiatry will be joining the new specialist training schemes. We hope this paper will help to inform the process of recruitment and selection and provide other scheme organisers with points to help them devise their own procedures.

\section{Declaration of interest}

The authors are honorary joint coordinators of the Mersey Regional Rotational Training Scheme.

\section{Acknowledgements}

We thank Emma Hulme, Dawn McLoughlin and Christine Withey of the Human Resource Department, Merseycare NHS Trust.

\section{References}

DEPARTMENT OF HEALTH (2004) DONALDSON, L. (2002) Unfinished Modernising Medical Careers: The Next Business: Proposals for Reform of the Steps. The Future Shape of Foundation, Senior House Officer Grade - A Paper Specialist and General Practice Training for Consultation. Department of Programmes. Department of Health. Health.

*Megan Munro Consultant Psychiatrist, Stein Centre, St Catherine's Hospital Birkenhead,Wirral CH42 0LQ, email Megan.Munro@cwpnt.nhs.uk,

Michael Wesson Consultant Psychiatrist, The Hesketh Centre, Southport, MarkTheophanous Consultant Psychiatrist, The Stewart Unit, Peasley Cross Wing, Merseyside 